\title{
Análisis crítico del ajuste secundario: ¿Todo ajuste por precios de transferencia implica una disposición indirecta de renta como sostiene la SUNAT?(*)
}

\author{
Critical analysis of secondary adjustment: Does all adjustment for transfer \\ prices imply an indirect disposition of income as SUNAT says?
}

\author{
Renee Antonieta Villagra Cayamana ${ }^{(* *}$ \\ Pontificia Universidad Católica del Perú (Lima, Perú)
}

\begin{abstract}
Resumen: La Administración Tributaria como consecuencia de las fiscalizaciones de precios de transferencia ha venido realizando ajustes secundarios determinando la existencia de dividendos presuntos gravados con las tasas del $4.1 \%$ o $5 \%$ en base a cualquier ajuste a la base imponible del Impuesto a la Renta por Precios de Transferencia efectuado por ella; sin embargo, consideramos que el ajuste secundario, conforme lo está llevando a cabo la SUNAT, no tiene asidero legal; tal posición ha sido corroborada por recientes pronunciamientos del Tribunal Fiscal los cuales analizaremos en el presente trabajo.
\end{abstract}

Palabras clave: Precios de transferencia - Ajuste secundario - Dividendo presunto Impuesto a la renta del Perú

\begin{abstract}
Tax Administration has issued resolutions assessing deemed dividends as secondary adjustments with the rates of $4.1 \%$ or $5 \%$ as a consequence of having proposed a primary adjustment in a transfer pricing audit. However, we believe this assessment, in the way that SUNAT is applying it, does not have legal basis. This position has been ratified by recent Sentences issued by the Fiscal Tribunal.
\end{abstract}

Key words: Transfer pricing - Secondary adjustment - Constructive dividends - Peruvian income tax

$\left(^{*}\right) \quad$ Nota del Editor: este artículo fue recibido el 2 de septiembre de 2020 y su publicación fue aprobada el 5 de octubre de 2020.

$\left({ }^{* *}\right)$ Profesora ordinaria del Departamento de Derecho de la PUCP. Consultora en Tributación Internacional y Precios de Transferencia. ORCID: https://orcid.org/0000-0002-4054. Correo electrónico: rvillagra@pucp.edu.pe 
Análisis crítico del ajuste secundario: ¿Todo ajuste por precios de transferencia implica una disposición indirecta de renta como sostiene la SUNAT?

Critical analysis of secondary adjustment: Does all adjustment for transfer prices imply an indirect disposition of income as SUNAT says?

\section{Introducción}

La investigación realizada trata de los ajustes secundarios y su aplicación en el Perú, tema que, a diferencia de la mayoría de vinculados a precios de transferencia, no constituye un estándar internacional, sino que corresponde exclusivamente a la legislación interna de los países. En tal sentido, la posición de la OCDE ${ }^{(1)}$ con relación a los ajustes secundarios ha sido siempre neutral, en tanto no los prohíbe ni los recomienda y más bien se mantiene cauta en sus lineamientos respecto a esta modalidad de ajuste, desarrolla al detalle la problemática que puede generar este tipo de ajustes e invoca a los países y a sus administraciones tributarias a evitar cualquier situación de doble o múltiple imposición que pudiera generarse y, en el marco de los $\mathrm{CDI}^{(2)}$, aboga por la solución de los problemas que ha identificado a través de procedimientos de acuerdo mutuo.

En nuestro país, la Administración Tributaria dentro de las fiscalizaciones de precios de transferencia que llevaba a cabo los primeros años de vigencia de tal régimen, originalmente se limitaba a emitir la Resolución de Determinación del Impuesto a la Renta por los ajustes de precios de transferencia y la correspondiente Resolución de Multa por la infracción prevista por el artículo 178 numeral 1 del Código Tributario (Villagra, 2020 , p. 28). Sin embargo, posteriormente, además del ajuste citado a la base imponible del Impuesto a la Renta empresarial, la SUNAT ha venido determinando en sus fiscalizaciones, sea definitivas o parciales, la existencia de dividendos presuntos asumiendo la existencia de disposición indirecta de renta en calidad de ajustes secundarios como consecuencia de tales incrementos de la base imponible del Impuesto a la Renta empresarial, al margen de cualquier otra consideración.

La base legal citada por la SUNAT en las determinaciones de los dividendos presuntos es el artículo 24-A, inciso g de la $\operatorname{LIR}^{(3)}$ por considerar que los ajustes de precios de transferencia significaban una disposición indirecta de dicha renta no susceptible de posterior control tributario. En el presente artículo, partiendo por conocer la definición y alcances que la doctrina reconoce a los ajustes secundarios, se expone la posición de la OCDE así como la problemática técnica y práctica que el citado ente ha identificado en tales ajustes a nivel internacional, se hace una revisión de la legislación comparada, se analiza el inciso g del artículo 24-A de la LIR conforme a una interpretación histórica, literal y finalista; se plantea el problema de la determinación de una "presunción sobre presunción", para, finalmente, conocer los pronunciamientos del Tribunal Fiscal sobre el ajuste secundario y la evolución de los mismos.

Cabe precisar que el tratamiento de la OCDE a los ajustes secundarios, está previsto desde las Directrices de la OCDE ${ }^{(4)}$ de 1995 en los lineamientos 4.67 a 4.77 (1995, pp. 7173); asimismo, se encuentra en las Directrices del 2010 en los lineamientos 4.66 a 4.76 (pp. 179-183); no obstante, para efecto de este análisis se tomará en cuenta lo recogido en las Directrices de la OCDE del 2017 en sus lineamientos del 4.68 a 4.78 (2017b, pp. 223-226).

\section{Definición de ajuste secundario}

El glosario de las Directrices de Precios de Transferencia de la OCDE señala que el ajuste secundario es el que resulta de la aplicación de un impuesto a una operación secundaria (2017b, p. 8) $)^{(5)}$, a su vez, la operación secundaria viene a ser una "construcción teórica a la que proceden determinados países en virtud de su legislación interna después de haber propuesto un ajuste primario a fin de realizar una asignación efectiva de los beneficios compatible con este ajuste primario" (2017, p. 35). En la misma línea, el $\mathrm{CIAT}^{(6)}$ considera a los ajustes secundarios como "construcciones teóricas" de alcance puramente doméstico pertenecientes a los países que llevan a cabo ajustes primarios a efecto de "facilitar"

(1) Este término hace referencia a la Organización para la Cooperación y el Desarrollo Económico.

(2) Este término se refiere a los Convenios para evitar la doble imposición y también son llamados convenios fiscales.

(3) Esto hace referencia al Texto Único Ordenado de la Ley del Impuesto a la Renta aprobado mediante Decreto Supremo 179-2004-EF (publicado el 08 de diciembre de 2004).

(4) Estas directrices de la OCDE son Guías sobre Precios de Transferencia para Empresas Multinacionales y Administraciones Fiscales, aprobadas por el Consejo de la Organización para la Cooperación y Desarrollo Económico.

(5) Es preciso señalar que con relación a la definición de ajuste secundario y operación secundaria el Glosario de las anteriores versiones de las Directrices de la OCDE correspondientes a 1995 y 2010 contienen la misma literalidad que la versión 2017 (1995, p. 12 y p. 16) (2010. p. 31 y p. 38)

(6) Esto hace referencia al Centro Interamericano de Administraciones Tributarias. 
la determinación de renta presunta ${ }^{(7)}$ como consecuencia del ajuste primario $\left(2019\right.$, p. 80) ${ }^{(8)}$.

Para la OCDE, con la realización de un ajuste primario se "asume" la existencia de una operación "presunta" también conocida como operación secundaria (2017b, p. 223), en tal sentido, el ajuste secundario que abordaremos corresponde a la presunción prevista por ley y no corresponde a la "recalificación" o "recaracterización" que, por ejemplo, España contempla en su legislación ${ }^{(9)}$ y que denomina ajuste secundario(10). López-Hermoso define al ajuste secundario español como "la recalificación de rentas que se produce como consecuencia de atribuir el tratamiento tributario que corresponda a la diferencia entre el valor convenido entre partes vinculadas y el valor de mercado de la operación". El mismo autor explica que el principio que subyace en la introducción de tal ajuste secundario es la prevalencia del fondo sobre la forma, atendiendo al flujo de renta y los desplazamientos patrimoniales que representan la diferencia entre el valor de mercado y el valor convenido (2010, p. 716). Cosín explica que los ajustes secundarios en España son consecuencia de diversos análisis en fiscalización, tales como de los recursos de la empresa, análisis estratégico, análisis de grado de diversificación e integración a efecto de "medir las economías de alcance o verticales y las economías de escala u horizontales necesarios para un ajuste secundario", lo cual descarta que se trate de una presunción (2007, p. 460).

\section{Posición de la OCDE con relación a los ajustes secundarios}

Es importante partir de la premisa que la OCDE con relación a los ajustes secundarios tiene una posición neutral, en tanto no prohíbe ni obliga a las legislaciones de los diferentes países a incorporar los ajustes secundarios (2017b, p. 224), conforme se desarrollará más adelante.

Los ajustes correlativos no son los únicos que pueden producirse como consecuencia de un ajuste primario de precios de transferencia. Recordemos que los ajustes primarios en el ámbito internacional ${ }^{(11)}$ conforme al Glosario de las Directrices de la OCDE son aquellos mediante los cuales la Administración Tributaria de una jurisdicción modifica la base imponible de una sociedad en virtud del principio de libre concurrencia, a operaciones en las que interviene una parte vinculada de una segunda jurisdicción (2017b, p. 8). Por su parte, los ajustes correlativos son los ajustes de la deuda tributaria de la empresa vinculadas determinada en una segunda jurisdicción fiscal llevado a cabo por la administración tributario como consecuencia del ajuste efectuado en la otra jurisdicción, con el fin de lograr la distribución coherente de los beneficios entre ambas jurisdicciones (2017b, p. 8).

En tal sentido, conforme señala el lineamiento 4.68 de las Directrices, si bien los ajustes primarios y sus ajustes correlativos modifican la asignación de beneficios imponibles dentro de un grupo multinacional para efecto tributario "no alteran el hecho de que el excedente de beneficio correspondiente al ajuste no es compatible con el resultado que se hubiera obtenido si las operaciones vinculadas se hubieran realizado en condiciones de plena competencia" (2017b, p. 223). La OCDE se refiere a que en condiciones semejantes una operación llevada a cabo entre partes independientes, además del Impuesto a la Renta empresarial correspondiente a la mayor utilidad que se determina en el ajuste de precios de transferencia, daría lugar al gravamen de dividendos por la distribución de la ganancia, situación que no se soluciona con el ajuste primario y el correlativo que están orientados al Impuesto a la Renta a cargo de las empresas exclusivamente.

\subsection{Modalidades de ajustes secundarios según la OCDE}

Para lograr que la "asignación efectiva de los beneficios" sea conforme con el ajuste primario de los precios de transferencia, algunos países asumen la existencia de una operación presunta también conocida como operación secundaria con la sola realización de un ajuste, en la cual se trata el exceso de

(7) El documento del CIAT redactado en inglés alude a "deemed income".

(8) Cabe señalar que los Manuales de la ONU (Manual Práctico de Precios de Transferencia para países en desarrollo de la ONU) en ninguna de sus versiones alude al ajuste secundario (ONU, 2013, p. 2017).

(9) Desde el año 2006, introducido por la Ley 36/2006 del 26 de noviembre de 2006 dentro de las medidas para la prevención del fraude fiscal.

(10) El concepto que asume Tartarini en su análisis del ajuste secundario está referido al modelo español que no corresponde a una presunción sino más bien a una recaracterización (2016, p. 36).

(11) Que es aquel al que se refieren en general las Directrices de la OCDE. 
Análisis crítico del ajuste secundario: ¿Todo ajuste por precios de transferencia implica una disposición indirecta de renta como sostiene la SUNAT?

Critical analysis of secondary adjustment: Does all adjustment for transfer prices imply an indirect disposition of income as SUNAT says?

beneficio resultante o consecuencia del ajuste primario sobre la renta empresarial como si se hubiese transferido de alguna otra forma y se grava en consecuencia $(2017$, p. 223).

Según los lineamientos de la OCDE, existen diversas modalidades o formas que puede adoptar la operación secundaria conforme a la legislación de algunas jurisdicciones, entre otras: (i) de dividendos presuntos, (ii) de aportes presuntos de fondos propios o (iii) de préstamos presuntos ${ }^{(12)}$. La OCDE grafica las modalidades (i) y (iii) con los siguientes ejemplos:

i. Modalidad de la operación secundaria a través de la consideración de la existencia de dividendos presuntos

La Administración Tributaria que realiza un ajuste primario sobre la renta de una filial de una matriz extranjera puede tratar el excedente de beneficio de la matriz extranjera como un dividendo percibido, gravado y sometido a una retención en la fuente. En este caso, es posible que la filial haya pagado a su matriz extranjera un precio de transferencia excesivo o sobrevaluado para evitar la retención a los dividendos en el país de la fuente (2017b, p. 223).

La OCDE califica a los dividendos presuntos como modalidad de operación secundaria como un mecanismo para prevenir la evasión fiscal, constituyendo su objetivo el intentar "subsanar la diferencia entre los beneficios imponibles ajustados y los inicialmente contabilizados" (2017b, p. 223).

ii. Modalidad de la operación secundaria a través de la consideración de la existencia de un préstamo presunto

Bajo esta modalidad la Administración Tributaria que realiza un ajuste primario sobre la renta de una empresa vinculada trata el exceso de beneficio de la empresa como un préstamo presunto de una parte vinculada a la otra, supuesto en el que se entiende que "surge la obligación de reembolsar el préstamo". La administración tributaria que lleva a cabo el ajuste primario puede aplicar el principio de plena concurrencia al supuesto préstamo a través de la imputación de intereses valorados conforme al principio de plena competencia considerando la tasa de interés a aplicar, la fecha en la que deben atribuirse los pagos por concepto de intereses y evaluando la procedencia de la capitalización de intereses. Esta modalidad de préstamo presunto puede involucrar no solamente el año al que se refiere el ajuste primario, sino también los años siguientes hasta la oportunidad en que se considere reembolsado el préstamo presunto (2017b, p. 224).

\subsection{Dificultades técnicas de los ajustes secundarios}

En el lineamiento 4.70 de las Directrices de la OCDE, se admite que el ajuste secundario puede generar situaciones de doble imposición excepto en los casos en los que el otro país conceda un crédito o cualquier otra forma de desgravamen por el impuesto adicional que resulte del ajuste secundario. Tal situación es expuesta por la OCDE al manifestar que cuando el ajuste secundario siga la modalidad de dividendo presunto, la retención en la fuente que se genera podría no ser materia de desgravamen en los casos en los que la legislación doméstica del otro Estado no considere la existencia de una recepción presunta de los dividendos (2017b, p. 224).

Conforme se ha señalado antes, la OCDE no prohíbe ni obliga a las legislaciones de los diferentes países a efectuar ajustes secundarios, así lo reconoce en el Lineamiento 4.71 de las Directrices, remitiéndose a los Comentarios correspondientes al párrafo 2 del artículo 9 del MCOCDE ${ }^{(13)}$ los cuales señalan que tal artículo no trata de los ajustes secundarios, sino más bien de los ajustes correlativos lo cual se debe a que en líneas generales, la finalidad de los CDI es evitar la doble imposición y prevenir la evasión fiscal con relación a los impuestos sobre la renta y el patrimonio. La OCDE admite que muchos países no practican ajustes secundarios e identifica dos razones: por una cuestión práctica en los casos en los que la legislación doméstica lo permite o debido a que el derecho interno de algún país no los autoriza. En tal sentido, algunos países podrían negarse al desgravamen de los ajustes secundarios efectuados por otros países y, de hecho, conforme a lo previsto en el artículo 9 de los $\mathrm{CDI}$ no están obligados a hacerlo (2017b, p. 224).

\subsection{Dificultades prácticas de los ajustes secundarios}

El lineamiento 4.72 de las Directrices señala que algunos países rechazan o se oponen

(12) La versión en inglés de las Directrices de la OCDE aluden a "Secondary transactions may take the form of constructive dividends, constructive equity contributions, or constructive loans" (2017a, p. 30).

(13) Este término hace referencia al Modelo de Convenio Tributario a la Renta y al Capital (Model Tax Convention on Income and Capital) 
a los ajustes secundarios por las dificultades prácticas que presentan. A título de ejemplo, manifiestan que, en el supuesto de un ajuste primario entre dos sociedades con una relación paralela en el organigrama del grupo, el ajuste secundario "puede producir la distribución en cadena de un dividendo teórico por una de estas sociedades hasta la sociedad matriz común, seguida de aportaciones presuntas de fondos propios en sentido inverso por la cadena de propiedad hasta la otra sociedad que interviene en la operación". En esa situación es posible construir teóricamente un gran número de operaciones, planteando cuestionamientos sobre la procedencia de que en "otros países deberían desencadenarse consecuencias tributarias más allá de las que se relacionan con la operación para la que se efectuó el ajuste primario". La OCDE admite que la situación descrita podría evitarse asimilando la operación secundaria a un crédito asumiendo la existencia de un préstamo; no obstante, reconoce que la mayoría de los países no utiliza los préstamos presuntos con esta finalidad, en tanto éstos plantean por sí mismos problemas con relación a los intereses imputados (2017b, p. 224).

La OCDE considera inapropiado considerar a los accionistas minoritarios como beneficiarios de un dividendo presunto, en la medida en que no son parte de las operaciones vinculadas y que, "en consecuencia, no han recibido un exceso de pagos, como aun cuando un dividendo no proporcional pueda considerarse incompatible con las disposiciones aplicables del derecho de sociedades". Adicionalmente, la OCDE reconoce que un ajuste secundario puede reducir excesivamente la carga fiscal global del grupo multinacional como resultado de la interacción con el sistema de crédito por impuesto extranjero (2017b, p. 225).

Ante el escenario descrito, dadas las dificultades existentes, en el lineamiento 4.73 de las Directrices la OCDE señala la conveniencia de que las administraciones tributarias cuando lleven a cabo ajustes secundarios reduzcan al mínimo el riesgo de doble imposición que pudiera derivarse de ellos, excepto en las situaciones en las que el proceder o comportamiento del contribuyente denote una intención de disfrazar un dividendo con la finalidad de evitar la retención en la fuente (2017b, p. 225).

Asumimos que en el escenario de una operación internacional que involucra más de un país, la OCDE ha identificado que ciertos países que practican ajustes secundarios ofrecen al contribuyente al que se le ha determinado el ajuste primario una opción que le permite evitar el ajuste secundario, "haciendo que el grupo multinacional del que forma parte repatríe el exceso de beneficios, a fin de adecuar sus cuentas al ajuste primario". La repatriación podría efectuarse bajo dos modalidades: (i) constituyendo una cuenta por cobrar, o (ii) reclasificando otras transferencias, "por ejemplo los pagos de dividendos cuando el ajuste se efectúa entre una sociedad matriz y su filial, como el pago de un precio de transferencia adicional (cuando el precio inicial fuese demasiado bajo) o como el reembolso de una parte del precio de transferencia (cuando el precio inicial fuese demasiado elevado)" (2017b, p. 225).

La OCDE reconoce que en un régimen de exención el beneficiario pierde cualquier crédito fiscal indirecto o, de ser el caso, el beneficio de una exención del dividendo; así como el crédito por la retención en la fuente que se hubiese acordado para el dividendo "cuando la repatriación implica la reclasificación de un pago de dividendos" y el importe del dividendo (hasta el importe del ajuste primario) no se incluye en la renta bruta del beneficiario (porque ya se habrá tomado en cuenta en el ajuste primario) (2017b, p. 225).

Por otro lado, según el lineamiento 4.76, cuando la repatriación se traduce en la constitución de una cuenta por cobrar "las rectificaciones de los flujos efectivos de tesorería se escalonarán en el tiempo, pudiendo limitarse el plazo de liquidación de esta cuenta por el derecho interno. Tal planteamiento es similar a la utilización de un préstamo presunto como operación secundaria para explicar el exceso de beneficio que se encuentra en manos de una de las partes que intervienen en la transacción vinculada. Los intereses devengados por la cuenta podrían generar sus propias consecuencias tributarias, lo que puede complicar el proceso según la fecha en que comiencen a devengarse de acuerdo con la legislación doméstica. La OCDE considera que algunos países pueden renunciar a gravar los intereses devengados por estas cuentas como parte de un acuerdo entre autoridades competentes (2017, p. 226).

Adicionalmente, el lineamiento 4.77 de las Directrices desarrolla el problema que se presenta cuando se intenta una repatriación, en cuyo caso se plantea la duda de saber "cómo deben registrarse tales pagos o acuerdos en la contabilidad del contribuyente que repatría los pagos a su empresa asociada, de forma que esta y la administración tributaria del país en cuestión estén informadas de que se ha procedido o previsto la repatriación". La OCDE señala que la forma que la repatriación adopte determinará su contabilización 
Análisis crítico del ajuste secundario: ¿Todo ajuste por precios de transferencia implica una disposición indirecta de renta como sostiene la SUNAT?

Critical analysis of secondary adjustment: Does all adjustment for transfer prices imply an indirect disposition of income as SUNAT says?

efectiva ${ }^{(14)}$ y que, adicionalmente, pueden plantearse problemas en lo referente a las ganancias y pérdidas por el cambio de moneda (2017, p. 226).

En el lineamiento 4.78 , la OCDE partiendo del reconocimiento efectuado en 1995 (1995, p. 73) al igual que en el año 2017 (2017b, p. 226) que sus países miembros no tienen mucha experiencia en los ajustes secundarios, recomienda que los acuerdos entre contribuyentes y administraciones tributarias relativas a las repatriaciones que vayan a efectuarse se traten en el contexto del procedimiento amistoso que se haya iniciado con referencia al ajuste primario correspondiente.

\section{Legislación comparada}

Del análisis de la legislación de precios de transferencia de los países conformantes de la Alianza del Pacífico se observa que Chile, Colombia y México no contemplan el ajuste secundario. Sin embargo, llama poderosamente la atención que según el CIAT la administración tributaria del Perú haya reportado la "rara" aplicación de los ajustes secundarios en la práctica (2019, p. 80) ${ }^{(15)}$, lo cual se contradice con lo observado en la práctica profesional y lo que fluye de los pronunciamientos reiterados del Tribunal Fiscal que, al margen de su fallo, ponen en evidencia la frecuente determinación de ajustes secundarios como dividendos presuntos en las fiscalizaciones de precios de transferencia.

El CIAT, en el estudio comparativo de la normatividad de los diferentes países que lo conforman señala que República Dominicana, Jamaica y Venezuela tienen legislación relativa al uso de ajustes secundarios (2019, p. 80).

\section{5. Ámbito de aplicación del inciso $\mathrm{g}$ del artículo 24A de la LIR conforme a una interpretación histórica, literal y finalista}

Cabe señalar que ley no ha creado una presunción específica para los ajustes secundarios de precios de transferencia.
Por su parte, consideramos que conforme a una interpretación histórica, literal y finalista del inciso g del artículo 24-A de la LIR no se encuentran gravados con dividendos presuntos la mayor renta correspondiente al ajuste primario de precios de transferencia. En todo caso, su aplicación debe ser interpretada de manera residual y excepcional, procediendo solo en casos de disposición indirecta no susceptible de posterior control tributario, debidamente probados por SUNAT.

Es preciso iniciar el análisis señalando que la LIR no ha establecido la presunción de ajuste secundario, en efecto, la referencia a este tipo de ajuste de precios de transferencia prevista en el artículo 109 inciso c del Reglamento de la LIR ${ }^{(16)}$, no tiene rango legal -como lo requiere el principio de reserva de ley establecido en el artículo 74 de la Constitución y la Norma IV del Título Preliminar del Código Tributario-. En efecto, la citada referencia del Reglamento de la LIR tiene como objetivo negar la aplicación del ajuste secundario en general, admitiendo su aplicación exclusivamente en una circunstancia excepcional:

"Como consecuencia del ajuste proveniente de la aplicación de las normas de precios de transferencia, no se generarán los dividendos a que se refiere el artículo 24-A de la Ley, salvo lo dispuesto en el inciso g del citado artículo".

Al respecto, cabe señalar que el artículo 24-A desde su incorporación a la LIR ha sido modificado en dos oportunidades conforme al siguiente detalle:

A) La Ley $27804^{(17)}$ vigente desde el 01 de enero de 2003 que incorporó el artículo 24-A a la LIR establecía en el inciso g que para efecto

(14) Al respecto, el lineamiento 4.77 señala:

"Por ejemplo, cuando la administración tributaria que efectúa el ajuste primario y el contribuyente que percibe el dividendo consideren un dividendo percibido como una repatriación, no es obligatorio que este tipo de acuerdo quede expresamente registrado en las cuentas de la empresa asociada que paga el dividendo, ya que tal acuerdo puede no afectar a la cuantía o a la calificación del dividendo que tiene en sus manos. Por otra parte, cuando se constituye una cuenta por pagar, tanto el contribuyente que registra la cuenta como la administración tributaria de ese país, deberán ser conscientes de que la cuenta se refiere a una repatriación, de manera que puedan identificarse claramente todos los reembolsos efectuados con cargo a la cuenta o los intereses procedentes de su saldo, y tratarlos de acuerdo con la legislación interna de ese país" (2017, p. 226).

(15) En el documento escrito en inglés se señala: "Only four of the countries in our study have regulations regarding the use of secondary adjustments: Dominican Republic, Jamaica, Peru and Venezuela. Furthermore, Peru reported the (rare) application of secondary adjustments in practice".

(16) Esto hace referencia al Reglamento de la Ley del Impuesto a la Renta aprobado mediante el Decreto Supremo 122-94-EF.

(17) Publicada el 02 de agosto de 2002. 
del Impuesto a la Renta se entiende por dividendos y cualquier otra forma de distribución de utilidades: "Toda suma o entrega en especie que, al practicarse la fiscalización respectiva, resulte renta gravable de la tercera categoría, siempre que el egreso, por su naturaleza, signifique una disposición indirecta de dicha renta, no susceptible de posterior control tributario (...)" (cursiva añadida).

Como se observa, la Ley 27804 , desde un inicio precisó que los dividendos a los que se refiere el citado inciso $\mathrm{g}$ constituyen egresos, lo que significa salidas de dinero o de bienes que impliquen una disposición indirecta de dicha renta a favor de accionistas $u$ otros, no susceptible de posterior control tributario.

B) Posteriormente, el Decreto Legislativo $945^{(18)}$ vigente desde el 01 de enero de 2004 modificó el inciso g del artículo 24-A de la LIR en los términos siguientes: "Toda suma o entrega en especie que, al practicarse la fiscalización respectiva, resulte renta gravable de tercera categoría, en tanto signifique una disposición indirecta de dicha renta, no susceptible de posterior control tributario, incluyendo las sumas cargadas al gasto e ingresos no declarados". Al respecto, la exposición de motivos de dicha norma precisó que se incorporaba esta modificación con el objetivo de unificar los conceptos que motivaban el gravamen de dividendos presuntos que se encuentran en el artículo 55 de la LIR. Asimismo, la citada exposición de motivos explicó que la incorporación en la Ley de otras formas de distribución de utilidades como supuestos de imposición por dividendos, era evitar el encubrimiento de la distribución de dividendos.

De lo señalado es posible inferir que la intención del legislador al incorporar el supuesto regulado en el inciso $\mathrm{g}$ del artículo 24-A de la LIR fue evitar que a través de la aplicación de operaciones "encubiertas" se deje de gravar los supuestos en los cuales los accionistas u otros se benefician de dichas operaciones.

Esta intención del legislador revelada por los antecedentes legislativos del inciso g del artículo 24-A y por la exposición de motivos de las referidas disposiciones, se encuentra alineada a la norma reglamentaria que, incorporada mediante Decreto Supremo 086-2004-EF(19), entró en vigencia el 05 de julio de 2004. Precisamente el artículo 13-B del Reglamento de la LIR estableció que dicho "desembolso o entrega" debe ser susceptible de haber beneficiado a los accionistas, participacionistas, titulares y en general a los socios y asociados. Es decir, que su ocurrencia genere o presumiblemente genere una ventaja patrimonial de manera directa o indirecta.
C) Tres años después mediante Decreto Legislativo $970^{(20)}$, vigente desde el 01 de enero de 2007 se modificó nuevamente el inciso g del artículo 24-A de la LIR conforme a los siguientes términos: "Toda suma o entrega en especie que resulte renta gravable de tercera categoría, en tanto signifique una disposición indirecta de dicha renta, no susceptible de posterior control tributario, incluyendo las sumas cargadas al gasto e ingresos no declarados" (cursiva añadida).

La exposición de motivos del referido decreto muestra con mayor claridad la real intención del legislador y finalidad de dicho artículo, pues establece que el fundamento de la LIR para aplicar la presunción de dividendos en el caso de disposición indirecta de rentas responde, precisamente, a la necesidad de equiparar el grado de imposición de las utilidades distribuidas a los accionistas, socios o asociados a través de acuerdos, con la disposición de dividendos u otras formas de distribución de utilidades, efectuada a través de mecanismos indirectos, como la asunción de gastos a cargo de los accionistas, participacionistas, titulares y en general, socios o asociados, o cualquier otro medio que implique una disposición indirecta de utilidades (cursivas añadidas).

Agrega la referida exposición de motivos que, el hecho de condicionar la distribución de utilidades a un proceso de fiscalización conlleva a que no se cumpla el fin perseguido, el cual es equiparar el tratamiento tributario de los dividendos distribuidos a través de acuerdos formales, con aquellos que se disponen de manera indirecta, motivo por el cual se elimina dicho requisito mediante la modificación introducida por la mencionada norma (cursiva añadida).

Adicionalmente, en la exposición de motivos se establece que, para la calificación de un gasto como disposición indirecta de renta, se debe comprobar el cumplimiento de las siguientes condiciones:

(i) La existencia de un desembolso o entrega que sea susceptible de beneficiar a los

(18) Publicado el 23 de diciembre de 2003.

(19) Publicado el 04 de julio de 2004

(20) Publicado el 24 de diciembre de 2006. 
Análisis crítico del ajuste secundario: ¿Todo ajuste por precios de transferencia implica una disposición indirecta de renta como sostiene la SUNAT?

Critical analysis of secondary adjustment: Does all adjustment for transfer prices imply an indirect disposition of income as SUNAT says?

accionistas, participacionistas, titulares y en general a los socios o asociados de personas jurídicas a que se refiere el artículo 14 de la ley; o (ii) la existencia de un desembolso o entrega que no sea susceptible de posterior control tributario, esto es, que el destino del dinero salido de caja o de los bienes salidos de almacén no pueda ser verificado o acreditado. En ese caso se presume una ventaja patrimonial a favor de los accionistas, participacioncitas, titulares y en general a los socios o asociados de personas jurídicas a que se refiere el artículo 14 de la ley.

Conforme a lo señalado, y según una interpretación histórica, literal y finalista, la norma analizada constituye una norma antielusiva, que pretende gravar la disposición indirecta de utilidades a favor de accionistas, participacionistas, titulares y en general a los socios o asociados de personas jurídicas, en los casos que se haya realizado la salida de dinero o de bienes cuyo destino sea susceptible de beneficiar a los mencionados sujetos, y también cuando no sea posible verificar su destino, dado que en estos casos se presume una ventaja patrimonial para tales personas.

En efecto, en reiterada jurisprudencia el Tribunal Fiscal ha establecido una relación entre la acreditación del destino de los desembolsos y la imposibilidad del posterior control tributario, entre otras, en las Resoluciones del Tribunal Fiscal 09845-10-2015, 06402-4-2014, 01387-10-2013,16253-9-2013, 06511-1-2010, 07646-8-2010, 11869-1-2008,05525-4-2008 y 11924-2-2008 se señala que no existe control tributario cuando no es posible determinar el destino de los desembolsos, razón por la cual se presume en estos casos que el beneficiario podría resultar ser el accionista, participacionista, titular, socio o asociado de personas jurídicas a que se refiere el artículo 14 de la LIR.

En tal sentido, se puede concluir que solo cuando nos encontremos ante un desembolso o entrega en especie, cuyo destino no pueda ser verificado o que siendo verificado sea susceptible de beneficiar al accionista, participacionista, titular, socio o asociado, de manera directa o indirecta ${ }^{(21)}$, se configurará el hecho imponible de dividendo presunto previsto en el inciso g del artículo 24-A de la LIR, siendo aplicable la tasa adicional regulada de $5 \%$.

Esta conclusión se encuentra alineada con una interpretación histórica, literal y finalista del inciso g del artículo 24-A de la LIR, dado que el propósito de la norma fue siempre equiparar el tratamiento tributario de los dividendos distribuidos a través de acuerdos formales, con aquellos que se "disponen" de manera indirecta ${ }^{(22)}$. Por tanto, la finalidad de la tasa adicional es gravar a las personas jurídicas respecto a aquellas sumas que sean susceptibles de beneficiar a los accionistas, participacionistas, titulares y en general socios o asociados, y que no hubieran sufrido dicha retención (disposición indirecta de rentas), lo cual ha sido confirmado por el Tribunal Fiscal en reiterada jurisprudencia.

\section{Análisis de la procedencia de la determinación de dividendos presuntos sobre la base de rentas diferentes a las reales ("presunción sobre presunción")}

A nivel de nuestro ordenamiento tributario no existe una norma legal que defina la presunción y la ficción. Sin embargo, en virtud de la Norma IX del Título Preliminar del Código Tributario, resulta de aplicación supletoria el Código Procesal Civil que sí los define, en línea con lo reconocido por la Administración en el Informe No 069-2014-SUNAT/5D0000 en el cual recurre al mismo cuerpo legal a efecto de definir qué se entiende por presunciones y ficciones legales.

El artículo 277 del Código Procesal Civil señala que la presunción es "el razonamiento lógico-crítico que a partir de uno o más hechos indicadores lleva al Juez a la certeza del hecho investigado. La presunción es legal o judicial".

Por otro lado, el artículo 288 de la norma en referencia señala que la ficción es "la conclusión que la ley da por cierta y que es opuesta a la naturaleza o realidad de los hechos, no permite prueba en contrario".

Al respecto, en doctrina se ha establecido que la presunción es "el resultado de un proceso lógico mediante el cual, de un hecho conocido cuya existencia es cierta, se infiere un hecho desconocido cuya existencia es probable", mientras que la ficción sería "una valoración jurídica (...) en virtud de la cual se atribuyen a determinados supuestos de hecho, efectos jurídicos que violentan e ignoran su naturaleza real" (Navarrine \& Asorey, 1985, p. 7).

(21) Tal es el caso de los gastos asumidos por la empresa y que son de cargo de los accionistas, socios o asociados.

(22) Exposición de motivos del Decreto Legislativo 970, pp. 35-44. 
Cabe señalar que si bien las normas tributarias no han definido en qué consiste la presunción, si se han regulado cómo debe proceder la determinación sobre base cierta y sobre base presunta. Precisamente, el artículo 63 del Código Tributario establece lo siguiente:

"Durante el período de prescripción, la Administración Tributaria podrá determinar la obligación tributaria considerando las bases siguientes:

1. Base cierta: tomando en cuenta los elementos existentes que permitan conocer en forma directa el hecho generador de la obligación tributaria y la cuantía de la misma.

2. Base presunta: en mérito a los hechos y circunstancias que, por relación normal con el hecho generador de la obligación tributaria, permitan establecer la existencia y cuantía de la obligación" (cursivas añadidas).

En base a ello se ha desarrollado a nivel jurisprudencial la diferencia entre ambas formas de determinación estableciendo, por ejemplo, en la Resolución del Tribunal Fiscal 06402-4-2014, lo siguiente:

Que la determinación sobre base cierta y sobre base presunta se diferencian en que, en la primera se conoce de manera directa la realización del hecho generador de la obligación tributaria, el periodo al que corresponde y la base imponible, mientras que en la segunda estos datos son obtenidos por estimaciones o suposiciones efectuadas sobre hechos ciertos vinculados al nacimiento de la obligación tributaria, criterio recogido en reiteradas resoluciones de este Tribunal, tales como las 5935-5-2006, 5691-1-2005 y 9826-32001, debiendo añadirse que para efectuar una determinación sobre base presunta es indispensable la existencia de una causal debidamente acreditada, conforme lo dispone en artículo 64 del Código Tributario (cursivas añadidas).

De lo expuesto se desprende que el alcance a nivel tributario de los términos "presunción" y "ficción legal" guarda relación con las normas del Código Procesal Civil y la doctrina citada en párrafos anteriores. En tal sentido, para aplicar una presunción debemos partir siempre de un hecho cierto y conocido ${ }^{(23)}$.

Lo señalado también es ratificado por la Administración en el Informe 069-2014-SUNAT/5D0000, en el cual señala que “(...) por definición, ambas figuras se diferencian por cuanto en la ficción no existe un proceso de deducción lógica que, a partir de uno o varios hechos conocidos, concluya en la certeza de otro, como sí ocurren en la presunción".

En tal sentido, una diferencia sustancial entre la ficción o presunción es la probabilidad de la existencia del hecho que le sirve de sustento, siendo probable en la presunción e improbable o incluso contrario a la realidad en la ficción.

Ahora bien, en el caso específico de la aplicación de dividendos presuntos, el Tribunal Fiscal ha reconocido en reiterada jurisprudencia ${ }^{24)}$ que la aplicación de los mismos (i) constituye una presunción; y, (ii) que no corresponde aplicar dividendos presuntos a los ingresos determinados en base a un procedimiento presuntivo, pues ello implicaría aplicar una presunción sobre otra presunción. Dicha afirmación se basa en la naturaleza de las presunciones que hemos desarrollado líneas arriba, pues no podemos partir de una presunción - en tanto no es un hecho cierto - para aplicar en base a ella otra presunción.

En tal sentido, la aplicación de una presunción como la de los dividendos presuntos exige partir de un hecho cierto y por ello no sería posible partir de la determinación de un ajuste de precios de transferencia aplicado por la Administración Tributaria que tiene connotación exclusivamente "valorativa"(25) y que es reconocido por la OCDE como una "aproximación razonable", en tanto no podría implicar disposición indirecta de renta que no tiene posterior control tributario(26). Cabe recalcar que la penúltima oración del lineamiento 1.13 de las Directrices señala que "Es importante no perder de vista el objetivo de llegar a una aproximación razonable de lo que sería un resultado de plena competencia basado en información fiable" (2017b, p. 44) (cursivas añadidas).

(23) La Resolución del Tribunal Fiscal 00045-3-2002 señala "Que por definición la base de una presunción legal, debe tener como punto de partida un hecho cierto y conocido, y por lo tanto debidamente probado (...)"

(24) Resoluciones del Tribunal Fiscal 06402-4-2014, 16253-9-2013, 450-2-2001, 244-4-2000, 742-2-2000, entre otras.

(25) Tal situación es discutible en el caso de la prestación de servicios gratuita en la que la SUNAT reconoce la existencia de una "renta imputada" en el texto del primer párrafo del artículo 32 aplicable tanto a partes independientes como a vinculadas.

(26) Salvo situaciones excepcionales como podría ser la aplicación de la Norma XVI del Título Preliminar del Código Tributario en la que sea posible "controlar" la disposición indirecta de renta. 


\section{Pronunciamientos del Tribunal Fiscal emitidos el 2019}

Del análisis de los casos que ha resuelto el Tribunal Fiscal con relación a la determinación de dividendos presuntos en las fiscalizaciones de precios de transferencia, en base a la información pública de la página web del citado ente, podemos identificar tres situaciones diferentes en función al comportamiento del contribuyente:

(i) Los casos en los que la empresa presenta una Declaración Jurada Rectificatoria reconociendo el reparo u observación por precios de transferencia en la determinación del Impuesto a la Renta de manera previa a la emisión de la Resolución de Determinación por los ajustes secundarios.

(ii) Las situaciones en las que empresa presenta una Declaración Jurada Rectificatoria reconociendo el reparo u observación por precios de transferencia en la determinación del Impuesto a la Renta de manera posterior a la emisión de la Resolución de Determinación por los ajustes secundarios; $y$

(iii) Los supuestos en los que la Administración Tributaria determina la existencia de dividendos presuntos en fiscalizaciones en las que la empresa no ha presentado ninguna rectificatoria reconociendo el ajuste a la base imponible del impuesto a la renta.

A continuación, desarrollaremos cada uno de estos casos:

7.1. Situaciones en las que el contribuyente presentó una Declaración Jurada Rectificatoria reconociendo el reparo u observación por precios de transferencia relativa a la base imponible del Impuesto a la Renta de manera previa a la emisión de la Resolución de Determinación por los ajustes secundarios.

Estos casos constituyen los hechos sobre los que el Tribunal Fiscal se ha pronunciado en sus Resoluciones 00358-4-2019, 01712-3-2019 y 01892-3-2019. En los pronunciamientos antes señalados el Tribunal Fiscal remitiéndose a lo señalado por él en las Resoluciones 02703-7-2009 y 04873-1-2012, entre otras, recurriendo a la interpretación histórica que hemos llevado a cabo en el numeral anterior, ha manifestado que: (...) la Tasa Adicional del Impuesto a la Renta se estableció con la finalidad de evitar que mediante gastos que no correspondía deducir, indirectamente se efectuara una distribución de utilidades a los accionistas, participacioncitas, titulares y en general socios o asociados de las personas jurídicas, sin afectar dicha distribución con la retención de la tasa de $4.1 \%$, sumas que califican como disposición indirecta de renta, lo que en doctrina se denomina "dividendos presuntos".

Adicionalmente, el Tribunal Fiscal, alude a sus Resoluciones 13887-4-2014 y 01215-9-2014, entre otras, en las que identifica como la razón de ser del inciso g del artículo 24-A de la LIR la nula posibilidad de realizar un seguimiento o control tributario de los ingresos al señalar que "el reconocimiento de un reparo mediante la presentación de una declaración rectificatoria, no autoriza la aplicación de la tasa adicional del Impuesto a la Renta debido a que el ingreso reconocido mediante declaraciones rectificadoras puede ser materia de posterior control tributario".

En tal sentido, razona el Tribunal Fiscal que en las situaciones en las que dentro del procedimiento de fiscalización la empresa presenta declaración rectificatoria por el Impuesto a la Renta del ejercicio fiscalizado en la que se incluye la observación por el ajuste en aplicación de las normas de precios de transferencia realizada por la SUNAT respecto de dicho impuesto y periodo no procede la aplicación de la Tasa Adicional del referido impuesto.

El Tribunal Fiscal tomando en consideración que el ingreso reconocido mediante declaraciones rectificatorias puede ser materia de posterior control tributario revoca las Resoluciones de la SUNAT y las deja sin efecto.

7.2. Situaciones en las que el contribuyente presentó una Declaración Jurada Rectificatoria reconociendo el reparo $u$ observación por precios de transferencia relativa a la base imponible del Impuesto a la Renta de manera previa a la emisión de la Resolución de Determinación por los ajustes secundarios

Esta situación está presente en el caso resuelto por el Tribunal Fiscal mediante su Resolución 01890-3-2019 en el cual la SUNAT señaló que la Resolución 00358-42019, que ha sido materia de análisis en el numeral 6.1, "no podría aplicarse al caso de autos, en tanto que la declaración ratificatoria se habría presentado con posterioridad a la emisión de la Resolución de Determinación" (cursiva añadida) y debido a que "existen limitaciones para efectuar un posterior control tributario a un no domiciliado".

Al respecto, el Tribunal Fiscal fue enfático al señalar que su Resolución 00358-4-2019 no distinguía la oportunidad de presentación 
de la Declaración Jurada Rectificatoria al señalar que "no distingue si la declaración rectificatoria fue presentada con anterioridad o con posterioridad a la emisión de la resolución de determinación vinculada a la aplicación de la aludida tasa adicional" determinando que carece de sustento lo alegado por la SUNAT en sentido contrario.

\subsection{Situaciones en las que la Administración Tributaria determina la existencia de dividendos presuntos al margen de si la empresa ha presentado declaración jurada rectificatoria}

En la Resolución 03049-4-2019, en un caso en el que la SUNAT determinó la existencia del dividendo presunto respecto de un ajuste al valor de mercado de operaciones realizadas entre partes vinculadas, el Tribunal Fiscal deja sin efecto tal determinación porque la Administración Tributaria no sustentó debidamente la aplicación de la Tasa Adicional del Impuesto a la Renta. El citado ente señala que "la Administración al emitir dicho acto no sustentó que en tal supuesto se estuviera ante una disposición indirecta de renta no susceptible de posterior control tributario, de acuerdo con lo previsto por el inciso g del artículo 24-A de la Ley del Impuesto a la Renta".

En su análisis, el Tribunal refiere a la Resolución 08000-3-2017 en la que manifiesta haber señalado que no corresponde considerar como dividendos presuntos al ajuste por subvaluación de ventas por aplicación de las reglas de valor de mercado, en tanto no se puede afirmar que dicho ajuste signifique una disposición indirecta de renta. El citado ente, manifiesta que: (...) se entiende que no todos los gastos reparables para efectos del Impuesto a la Renta deben ser cuantificados para aplicar la tasa del 4,1\%, toda vez que la referida tasa adicional solo es aplicable respecto de aquellos desembolsos cuyo destino no pueda ser acreditado fehacientemente, pues se entenderá que es una disposición indirecta de renta que no es susceptible de posterior control tributario, tal como se ha precisado en las Resoluciones del Tribunal Fiscal 12078-3-2015 y 02487-4-2017, entre otras.

Es preciso señalar que en este caso el contribuyente había presentado una declaración rectificatoria, no obstante, el Tribunal Fiscal deja de lado el argumento de la capacidad de la Administración Tributaria de efectuar el "posterior control tributario" expuesto en los numerales 6.1 y 6.2 para exigir el sustento por parte de la SUNAT de que se trata de una "disposición indirecta" no susceptible de posterior control tributario, al señalar:

Que de los fundamentos contenidos en la Resolución de Determinación se tiene que la Administración aplicó la Tasa Adicional de $4.1 \%$ al considerar que correspondía aplicar esta respecto del reparo ajuste a valor de mercado de las operaciones realizadas con partes vinculadas. establecido en el procedimiento de fiscalización, por el importe de S/
14'275,213.00; sin embargo, al tratarse de un ajuste efectuado por aquella a valor de mercado y considerando que la Administración al emitir dicho acto no sustentó que en tal supuesto se estuviera ante una disposición indirecta de renta no susceptible de posterior control tributario, de acuerdo con lo previsto por el inciso g del artículo 24-A de la Ley del Impuesto a la Renta, aunado al hecho que en el procedimiento de fiscalización se presentó la declaración rectificatoria por el Impuesto a la Renta del ejercicio 2013 (...) en autos no se encuentra debidamente sustentada la aplicación de la Tasa Adicional del Impuesto a la Renta, por lo que corresponde revocar la citada resolución de intendencia y dejar sin efecto la citada resolución de determinación impugnada".

En un caso similar al antes tratado, con la diferencia de que la empresa no presentó la Declaración Jurada Rectificatoria respecto al reparo por precios de transferencia, el Tribunal Fiscal, en la Resolución 6144-9-2019 dejó sin efecto la determinación del dividendo presunto debido a que la Administración Tributaria no sustentó la existencia de disposición indirecta de renta no susceptible de posterior control tributario.

\section{Conclusiones}

- El ajuste secundario, según lo concibe la OCDE, constituye siempre una presunción que presenta tres modalidades, siendo una de ellas la determinación de dividendos presuntos. Gran parte de los lineamientos de la OCDE dedicados a este ajuste están orientados a demostrar la extensa problemática técnica y práctica de tales ajustes. Ante tal situación, la citada entidad invoca a evitar situaciones de doble imposición que podrían presentarse por la aplicación de ajustes secundarios con la consecuente denegatoria de créditos o exenciones.

- La OCDE admite que sus países miembros no tienen mucha experiencia en los ajustes secundarios y que usualmente no se aplica el ajuste secundario por los problemas técnicos y prácticos que presenta. 
Análisis crítico del ajuste secundario: ¿Todo ajuste por precios de transferencia implica una disposición indirecta de renta como sostiene la SUNAT?

Critical analysis of secondary adjustment: Does all adjustment for transfer prices imply an indirect disposition of income as SUNAT says?

- Del análisis de la legislación comparada se observa que Colombia, Chile y México, países miembros de la Alianza del Pacífico, no contemplan el ajuste secundario en su legislación.

- El ajuste secundario que significan los dividendos presuntos en el Perú ha sido previsto como una excepción conforme al artículo 109 inciso c) del Reglamento de la LIR que, en principio, señala que no se generan los dividendos a que se refiere el artículo 24-A de la LIR como consecuencia del ajuste proveniente de la aplicación de las normas de precios de transferencia, salvo lo dispuesto en el inciso g) del citado artículo.

- La norma reglamentaria antes citada, no tiene rango legal como lo requiere el principio de reserva de ley establecido en el artículo 74 de la Constitución y la Norma IV del Título Preliminar del Código Tributario.

- Conforme a una interpretación histórica, literal y finalista del inciso g del artículo 24-A de la LIR se identifica que la misma constituiría una norma antielusiva, que pretende gravar la disposición indirecta de utilidades a favor de accionistas, participacionistas, titulares y en general a los socios o asociados de personas jurídicas, en los casos en los que se haya realizado la salida de dinero o de bienes cuyo destino sea susceptible de beneficiar a los mencionados sujetos, y también cuando no sea posible verificar su destino, dado que en estos casos se presume una ventaja patrimonial para tales personas.

- La aplicación de la presunción de dividendos, como cualquier presunción en general, exige partir de un hecho cierto, por ello no sería posible partir de la determinación de un ajuste de precios de transferencia efectuado por la Administración Tributaria dada su connotación "valorativa" y su carácter de "aproximación razonable" en base a un rango de precios o márgenes previstos por la LIR.

- La posición del Tribunal Fiscal en recientes Resoluciones que involucran dividendos presuntos como consecuencia de ajustes de precios de transferencia es que la Administración Tributaria debe probar la existencia de una disposición indirecta de renta no susceptible de posterior control tributario en el caso de las determinaciones de precios de transferencia reflejados en una mayor base imponible del Impuesto a la Renta. La exigencia del Tribunal antes señalada, se da al margen de la presentación (o no) de una declaración jurada rectificatoria relativa al ajuste de precios de transferencia.

- Consideramos que la exigencia del Tribunal Fiscal mencionada en la conclusión VIII deviene en una tarea muy difícil y casi imposible para la SUNAT, considerando que el ajuste por precios de transferencia no corresponde a una ciencia exacta, lo cual es evidenciado en la necesidad de recurrir a un rango de precios conforme a la LIR y al derivar de una "aproximación razonable" conforme reconoce la OCDE a las determinaciones de precios de transferencia.

- Lo antes señalado corrobora el carácter excepcional y residual de la determinación de dividendos presuntos como consecuencia de ajustes de precios de transferencia que en nuestro país se circunscribe a las situaciones en las que la SUNAT pueda demostrar plenamente la existencia de una disposición indirecta de renta no susceptible de posterior control tributario.

\section{Referencias bibliográficas}

Centro Interamericano de Administraciones Tributarias \& Sociedad Alemana para la Cooperación Internacional. (2013). El control de la Manipulación de los Precios de Transferencias en América Latina y el Caribe. CIAT. https://biblioteca. ciat.org/opac/book/5095

Centro Interamericano de Administraciones Tributarias \& Sociedad Alemana para la Cooperación Internacional. (2019). Transfer Pricing in Latin America and the Caribbean-A General Overview based on CIATData Transfer Pricing Information updated to November 2019. CIAT. https://biblioteca.ciat.org/opac/ book/5689

Cosín, R. (2007). Fiscalidad de los precios de transferencia. CISS.

López-Hermoso, J.C. (2010). El ajuste secundario. En T. Cordón (1. ${ }^{\text {a }}$ ed), Fiscalidad de los precios de transferencia (operaciones vinculadas) (pp. 715740). Ediciones CEF.

Navarrine, S. \& Asorey, R. (1985). Presunciones y ficciones en el derecho tributario: doctrina, legislación y jurisprudencia. Ediciones Depalma.

Organización para la Cooperación y el Desarrollo Económico. (1995). Directrices de la OCDE aplicables en materia de precios de transferencia a empresas multinacionales y administraciones tributarias. OCDE.

Organización para la Cooperación y el Desarrollo Económico. (2010). Directrices de la OCDE aplicables en materia de precios de transferencia a empresas multinacionales y administraciones tributarias 2010. Instituto de Estudios Fiscales (IEF). https://doi.org/10.1787/9789264202191-es 
Organización para la Cooperación y el Desarrollo Económico. (2017a). OECD Transfer Pricing Guidelines for Multinational Enterprises and Tax Administrations. OECD Publishing. https://doi. org/10.1787/tpg-2017-en

Organización para la Cooperación y el Desarrollo Económico. (2017b). Directrices de la OCDE aplicables en materia de precios de transferencia a empresas multinacionales y administraciones tributarias. Instituto de Estudios Fiscales (IEF). https://doi.org/10.1787/9788480083980-es

Organización de las Naciones Unidas. (2013). Practical Manual on Transfer Pricing for Developing Countries. United Nations. http://www.un.org/esa/ ffd/documents/UN_Manual_TransferPricing.pdf

Organización de las Naciones Unidas. (2017a). Model Double Taxation Convention between Developed and Developing Countries. United Nations. https://www.un.org/esa/ffd//wp-content/ uploads/2018/05/MDT_2017.pdf

Organización de las Naciones Unidas. (2017b). Practical Manual on Transfer Pricing for Developing
Countries. United Nations. http://www.un.org/esa/ffd/wp-content/ uploads/2017/04/Manual-TP-2017.pdf

Tartarini, T. (2017). El ajuste secundario en materia de precios de transferencia, notas sobre su naturaleza y deficiente regulación en el Perú. Ius Et Veritas, 24(52). http://revistas.pucp.edu.pe/index.php/ iusetveritas/article/view/16369

Trape, M. (2004). El Régimen Fiscal de los Precios de Transferencia. En T. Cordón (1. ${ }^{\text {a }}$ ed.), Manual de Fiscalidad Internacional (pp. 433472). Instituto de Estudios Fiscales (IEF).

Trape, M. (2010). Métodos de valoración. En T. Cordón (1. ${ }^{a}$ ed.), Fiscalidad de los precios de transferencia (operaciones vinculadas) (pp. 345-366). Ediciones CEF.

Villagra, R. (2008). Manual Los Convenios para Evitar la Doble Imposición y Prevenir la Evasión Fiscal: Con énfasis en los convenios vigentes en el Perú. En IFA Grupo Peruano, CDIs Convenios para Evitar la Doble Imposición Tributaria (pp. 15-28). IFA.

Villagra, R. (2019). La Red de Convenios para Evitar la Doble Imposición suscritos por los países de Sudamérica. En F. Serrano (9. ${ }^{\text {a }}$ ed.), Fiscalidad Internacional (pp. 1645-1685). Ediciones CEF.

Villagra, R. (2020). Resolución de casos que involucran Precios de Transferencia - Criterios del Tribunal Fiscal. Revista Análisis Tributario. 
